Quim. Nova, Vol. 25, No. 3, 372-378, 2002.

\title{
ALTERNATIVA ANALÍTICA PARA ESPECIAÇÃO FÍSICO-QUÍMICA DE MERCÚRIO EM ÁGUAS COSTEIRAS TROPICAIS
}

\author{
Rozane V. Marins* \\ Instituto de Ciências do Mar, Universidade Federal do Ceará, Av. Abolição, 3207, 60165-081 Fortaleza - CE \\ Heloísa Helena M. Paraquetti e Gisele A. Ayres \\ Departamento de Geoquímica, Universidade Federal Fluminense, Outeiro de São João Batista s/n, 24020-007 Niterói - RJ
}

Recebido em 5/2/01; aceito em 24/10/01

\begin{abstract}
ANALYTICAL ALTERNATIVE FOR THE PHYSICAL-CHEMICAL SPECIATION OF MERCURY IN TROPICAL COASTAL WATERS. The determination of the physical-chemical mercury speciation in tropical coastal waters using the derivatization technique with CVAFS detection was optimized. This methodology is able to separate the elementary, reactive, organic and total mercury phases with low operational costs. The importance of bromide chloride solution, the diluted aqua regia, used as the oxidative solution, and different compositions of the reductive solution of stannous chloride were tested and the better results for coastal waters are presented. The recuperation of the sum of the different phases ranges from 80 to $94 \%$ of the total $\mathrm{Hg}$ content in duplicates of different marine samples. The optimized methodology permits important studies on the mercury cycle in the coastal environment.
\end{abstract}

Keywords: mercury; physical-chemical speciation; coastal waters; CVAFS.

\section{INTRODUÇÃO}

A compreensão dos processos biogeoquímicos, sejam eles precipitação/dissolução, adsorção/dessorção, bioconcentração, desgazeificação/deposição atmosférica, dos quais participam os metais-traço nas regiões estuarinas e no oceano aberto necessita da determinação das diferentes espécies físico-químicas dos metais presentes. A especiação de um elemento é a determinação das formas físico-químicas individuais do elemento que somadas são iguais à concentração total desse elemento ${ }^{1}$.

Diferentes formas de distinguir espécies físico-químicas são empregadas em estudos ambientais ${ }^{2}$. A derivatização é um método de caráter operacional que define as formas dos elementos traço através do uso acoplado de técnicas analíticas de baixo custo operacional e técnicas de seleção física de espécies. A derivatização promove a separação entre as fases orgânicas e inorgânicas nas fases dissolvido e particulado de águas naturais. A modelagem matemática fundamentada em variáveis termodinâmicas e constantes de equilíbrio também é utilizada como estimativa acurada para a determinação das espécies de metais-traço em águas naturais ${ }^{3,4}$.

As regiões costeiras, zonas de alta atividade reacional devido às rápidas mudanças das condições ambientais que ocorrem devido à mistura das águas doces com as águas salinas, promovem modificações de importantes parâmetros tais como a força iônica, razões entre os maiores componentes, $\mathrm{pH}$, potencial de oxi-redução, turbidez, etc. Esses parâmetros vão modificar não somente a físico-química da solução aquosa como também modificar a biodisponibilidade dos metais-traço, que dependerá da especiação química desses elementos. A despeito dessas evidências tem sido dada pouca importância à especiação química, sendo determinadas somente espécies organometálicas individuais ${ }^{2}$. Técnicas de derivatização podem ser de grande interesse por relacionarem ciclos de especiação de grande interesse ambiental.

\footnotetext{
*e-mail: rmarins@fortalnet.com.br
}

Em região costeira subtropical foi observado que, embora haja grande capacidade de imobilização de mercúrio em sedimentos de fundo, esta retenção pode representar menos de $15 \%$ das entradas totais anuais do metal para a bacia de drenagem avaliada. O restante permanece ciclando nas águas estuarinas, disponível à biota local ou em parte sendo exportado para o oceano e/ou águas costeiras vizinhas $^{5}$.

Comparados os resultados obtidos sobre o balanço de mercúrio em área costeira subtropical não eutrofizada com outros relacionados na literatura internacional, foi demonstrado que o transporte através da coluna d'água é o principal passo no ciclo do mercúrio nesses ambientes, mais importante que o processo de deposição em sedimentos de fundo 6 .

Em águas, de um modo geral, há predominância da forma oxidada (divalente, que pode ou não estar associada a ligantes orgânicos ou inorgânicos) 7 . A espécie orgânica é de grande interesse uma vez que, em sua grande maioria, representa o metil-mercúrio, que é a espécie mais tóxica de mercúrio e pode facilmente ser incorporada pela biota ${ }^{8}$.

A importância da especiação físico-química pode ser exemplificada pelas observações feitas numa área do Pacífico Equatorial sobre a deposição atmosférica e a evasão gasosa de mercúrio no ambiente marinho ${ }^{9}$. Nesse estudo ficou comprovado que as taxas de evasão gasosa daquela região não podiam ser suportadas pelas taxas de deposição atmosférica, que é a principal fonte de mercúrio para os oceanos abertos. Através da modelagem dos resultados, ficou comprovado que essas taxas eram mantidas pelas entradas de mercúrio das águas de ressurgência, que encontraram nas águas de mistura ambiente propício a formação de $\mathrm{Hg}^{0}$. Ou seja, o metil-mercúrio pode em zonas de mistura encontrar ambiente propício à demetilação, gerando a forma elementar mais facilmente disponível à difusão gasosa, o que pode explicar parte do balanço geoquímico de mercúrio em ambientes costeiros.

A formação dos complexos de menor toxicidade que o metilmercúrio, tais como $\mathrm{CH}_{3} \mathrm{HgSH}$ ou $\mathrm{CH}_{3} \mathrm{HgSR}$, pode ser um processo regulador da contaminação da biota e explicar porque, em alguns 
ambientes, observam-se concentrações elevadas de mercúrio nas águas mas não na biota ${ }^{10}$.

Em áreas costeiras tropicais e subtropicais é praticamente inexistente esse tipo de estudo. Para que seja possível a compreensão dos processos geoquímicos responsáveis pela ciclagem do mercúrio na coluna d'água dessas áreas, foi realizada a otimização de metodologia de determinação de diferentes fases físico-químicas de mercúrio em águas estuarinas, através de técnicas de derivatização e detecção através da espectrometria de fluorescência atômica, utilizando-se a técnica de geração de vapor frio.

\section{PARTE EXPERIMENTAL}

As percentagens das principais espécies químicas de mercúrio presentes na água do mar são apresentadas na Tabela 1. Nessa Tabela o percentual de mercúrio elementar foi desconsiderado, entretanto sabe-se que essa fração pode apresentar valores importantes para a ciclagem de mercúrio no ambiente marinho ${ }^{11}$.

Tabela 1. Estimativa do percentual (\%) das principais espécies químicas de mercúrio presentes em águas salinas e salobras (6)

\begin{tabular}{|c|c|c|c|c|}
\hline \multirow{2}{*}{$\begin{array}{l}\text { Espécies } \\
\text { Químicas } \\
\text { Inorgânicas }\end{array}$} & \multirow[t]{2}{*}{$\begin{array}{l}\text { Água do mar } \\
{[\mathrm{Cl}]=0,7 \mathrm{M}}\end{array}$} & \multicolumn{3}{|c|}{$\begin{array}{c}\text { Água salobra } \\
{[\mathrm{Cl}]=0,2 \mathrm{mM}}\end{array}$} \\
\hline & & $\mathrm{pH}=6$ & $\mathrm{pH}=7$ & $\mathrm{pH}=8$ \\
\hline $\mathrm{HgCl}_{4}^{2-}$ & 65,8 & - & - & - \\
\hline $\mathrm{HgCl}_{3} \mathrm{Br}^{2-}$ & 12,3 & - & - & - \\
\hline $\mathrm{HgCl}_{3}^{-}$ & 12,0 & 0,1 & 0,1 & - \\
\hline $\mathrm{HgCl}_{2} \mathrm{Br}^{-}$ & 4,3 & - & - & - \\
\hline $\mathrm{HgCl}_{2}$ & 3,0 & 91,1 & 34,1 & 0,1 \\
\hline $\mathrm{HgOHCl}$ & 0,2 & 8,5 & 49,4 & 6,2 \\
\hline $\begin{array}{l}\mathrm{Hg}(\mathrm{OH})_{2} \\
\text { ORGÂNICAS }\end{array}$ & - & 0,2 & 16,4 & 93,7 \\
\hline $\mathrm{CH}_{3} \mathrm{HgCl}$ & 92,2 & 89,8 & 33,5 & 1,9 \\
\hline $\mathrm{CH}_{3} \mathrm{HgOH}$ & 5,1 & 8,4 & 65,8 & 98,1 \\
\hline $\mathrm{CH}_{3} \mathrm{Hg}^{+}$ & - & 1,9 & 0,7 & 0,04 \\
\hline
\end{tabular}

A quantificação do conteúdo total de $\mathrm{Hg}$ em águas marinhas aponta valores na ordem de 0,05 a 3,0 ng/ $1^{7,12-14}$. Entretanto, anteriormente ao uso de equipamentos dedicados a fluorescência atômica de mercúrio, valores mais elevados para águas marinhas foram reportados até mesmo em exercícios interlaboratoriais internacionais ${ }^{15}$. Uma vez que o conteúdo total representa a soma de todas as fases e formas do elemento em solução, é necessário que limites de detecção na ordem de centésimos de ng/l sejam alcançados para a determinação das diferentes espécies mercuriais.

\section{Amostragem e preservação de amostras}

Para adequação da metodologia a águas costeiras tropicais foram inicialmente feitos testes com o sistema de detecção com soluções padrões de cloreto mercúrico para colocação do equipamento em rotina de pesquisa; após essa primeira fase foram utilizadas amostras naturais de águas marinhas. As amostras foram coletadas utilizando-se garrafa de coleta do tipo fluxo contínuo, revestida de Teflon, que não provoca borbulhamento da amostra durante o processo de coleta, para que não haja perdas da fase gasosa. A estocagem foi feita em garrafas PET, refrigeradas à $4^{\circ} \mathrm{C}^{16,17}$.

As amostras para determinação das espécies mercuriais foram analisadas logo após a coleta, no intervalo máximo de quarenta e oito horas ${ }^{12,18}$. Esse tempo é determinado a fim de que as espécies de interesse permaneçam preservadas até determinação analítica final.

\section{Metodologia de detecção}

A determinação de mercúrio nas amostras de água foi realizada por espectrofotometria de fluorescência atômica usando a técnica de geração de vapor frio (CVAFS) com pré-concentração em ouro (um estágio) $)^{13}$.

A fluorescência é um fenômeno luminescente onde a emissão de fóton de estado eletronicamente excitado é alcançada a partir de um estado fundamental singlete. No estado singlete excitado, o elétron no orbital de mais alta energia tem spin em orientação contrária ao do segundo elétron no orbital inferior (elétrons emparelhados). A fluorescência é, portanto, um fenômeno de luminescência que se produz entre dois estados de mesma multiplicidade da molécula ${ }^{19,20}$.

Em geral, a fluorescência ocorre num comprimento de onda deslocado do comprimento de onda de absorção. Exceção feita para átomos na fase vapor, propriedade explorada pelos construtores do equipamento de fluorescência atômica dedicado a determinações de mercúrio. Ambas, a excitação e a fluorescência do átomo de mercúrio ocorrem a $253,7 \mathrm{~nm}^{19-21}$.

A intensidade da fluorescência atômica esta relacionada à concentração do mercúrio presente, é mais sensível do que a técnica de absorção atômica e linear para uma grande faixa de concentração.

A técnica de espectrometria de fluorescência atômica não sofre interferências positivas, entretanto, uma preparação inadequada da amostra pode resultar em falsa leitura devido ao espalhamento da luz por turbidez. Os principais componentes do fluxo de gás carreador que podem promover turbidez são vapores d'água ou de solventes orgânicos. Solventes orgânicos não são empregados nessa metodologia e vapores d'água são retidos em armadilhas existentes no sistema de geração e pré-concentração do analito ${ }^{19,21,22}$.

A principal interferência negativa da fluorescência (quenching) é causada pela presença de espécies moleculares na corrente de gás carreador. O quenching promovido pela presença dos halogenetos maiores, tais como brometo, pode ocorrer devido ao cruzamento intersistema para um estado excitado triplete, promovido por um acoplamento spin-órbita do singlete excitado do fluoróforo e o halogênio ${ }^{19,21}$. Enquanto isso, a presença do oxigênio na linha de detecção deprime a fluorescência do mercúrio através da formação de dois oxigênios singletes $\left(3^{+}\right)$.

Para que sejam evitadas interferências, a detecção é realizada em atmosfera de gás inerte ultrapuro ${ }^{20}$. Usualmente, é recomendada a pré-concentração do mercúrio em dois passos de dessorção térmica. No primeiro passo o vapor de mercúrio gerado para detecção é coletado numa armadilha de ouro e o efluente gasoso desprezado através do uso de uma válvula solenóide, evitando-se que o fluxo gasoso contendo os interferentes chegue à célula de deteção ${ }^{23,24}$.

$\mathrm{Na}$ técnica utilizada, o vapor frio de mercúrio foi gerado a partir do esquema ${ }^{24,25}$ apresentado na Figura 1. Nesse esquema, a corrente gasosa contendo o vapor de mercúrio, gerado no frasco I, e transportada por fluxo de argônio isento de mercúrio, a $760 \mathrm{ml} / \mathrm{min}$, é prétratada antes de chegar à armadilha de ouro. $\mathrm{O}$ tratamento consiste na lavagem em solução de $\mathrm{NaOH}$ (frasco II), em água (frasco III) e em banho de gelo (frasco IV), para prevenir o quenching promovido por substâncias tais como cloro, bromo e vapor d'água, formadas durante o processo de geração do vapor. Esse esquema permite que a medida do teor de mercúrio torne-se absoluta, uma vez que o elemento é diretamente relacionado ao sinal analítico através de uma equação matemática obtida da calibração do aparelho usando-se padrões sintéticos puros ${ }^{26}$, visto que no fluxo de medida somente a espécie mercúrio está presente, ou seja, na ausência de interferentes para qualquer razão do elemento em análise.

O sistema de geração do vapor de mercúrio é acoplado ao equipamento detetor através de tubos de vidro e de silicone. O tem- 


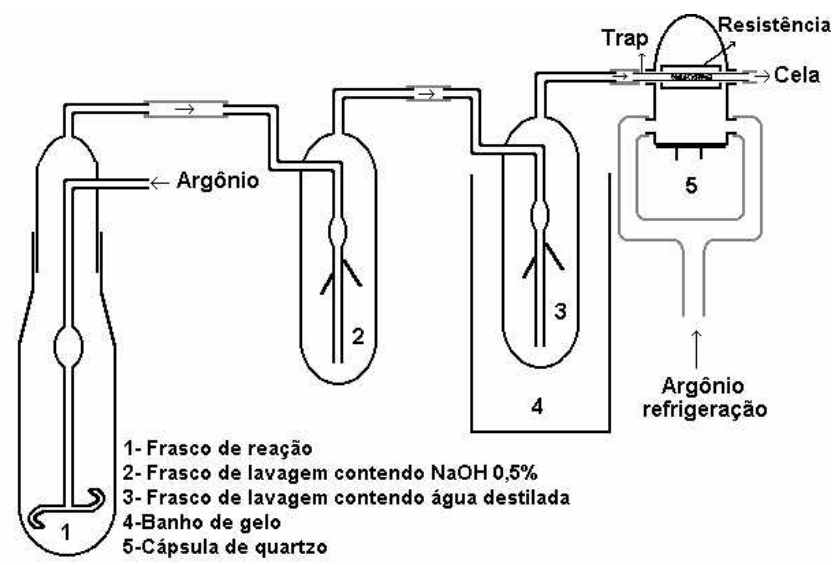

Figura 1. Esquema analítico da técnica de vapor frio utilizado para geração, lavagem e separação de $\mathrm{Hg}^{0}$, utilizado na espectrometria de fluorescência atômica para determinação de mercúrio 25

po de reação, purga e retenção em ouro, dessorção térmica do mercúrio da armadilha de ouro e conseqüente detecção são programados e controlados por um temporizador em série. Através da avaliação da intensidade relativa do sinal foram otimizados o fluxo de volatilização do vapor de mercúrio em $760 \mathrm{ml} / \mathrm{min}$, e o fluxo de arraste para a deteção em $40 \mathrm{ml} / \mathrm{min}$. O tempo de análise por amostra foi quantificado em $180 \mathrm{seg}$ para as espécies mercúrio total e reativo comprovando que a utilização desse sistema, como anunciado pelo fabricante, tem fins de suporte à pesquisa na área ambiental e pouco se aplica a medidas de rotina ${ }^{21}$. Para a espécie mercúrio elementar foram realizadas outras otimizações nesse trabalho.

A lâmpada do equipamento utilizado é uma lâmpada de vapor de mercúrio, a baixa pressão. Essa lâmpada apresenta maior intensidade do que a lâmpada de xenônio e fornece linhas muito finas do espectro de mercúrio, úteis à calibração ${ }^{19}$.

A detecção é feita no equipamento através de um tubo fotomultiplicador (PMT) que lê a célula através de um filtro monocromático em ângulo reto em relação à luz incidente. A luz direta não é vista pelo PMT, entretanto, a fluorescência produzida pelo mercúrio elementar na célula é multidirecionada e é observada pelo PMT. O diagrama de fluxo do equipamento de detecção é apresentado na Figura 2.

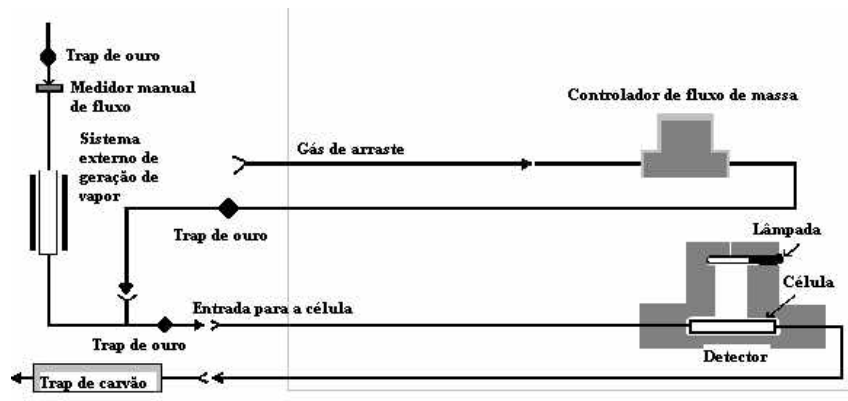

Figura 2. Diagrama do equipamento de fluorescência atômica acoplado ao esquema da técnica de vapor frio, modificado a partir de Tekran 21

A intensidade da fluorescência é diretamente proporcional à quantidade de mercúrio. Soluções padrões de concentração nas faixas desejadas são utilizadas para a construção da curva de calibração e calibração do equipamento. Essas soluções são preparadas a partir da solução-padrão MERCK de sais de $\mathrm{Hg}^{2+}, 1000 \mathrm{mg} \mathrm{L}^{-1}$ através de sucessivas diluições.
A aquisição dos resultados em sistema gráfico aumentava em minutos o sistema de obtenção de resultados e devido a isso foi substituído pela leitura direta do máximo da intensidade da fluorescência no sistema digital do equipamento de detecção.

\section{Metodologia de separação das espécies mercurais}

A separação das espécies químicas mercúrio elementar $\left(\mathrm{Hg}^{0}\right)$, mercúrio reativo (Hg react), mercúrio complexado fortemente a orgânicos (Hg org) e mercúrio total (Hgtot) foi obtida através das técnicas de redução seletiva ou derivatização, ${ }^{7,13,27}$ segundo o fluxograma apresentado na Figura 3.

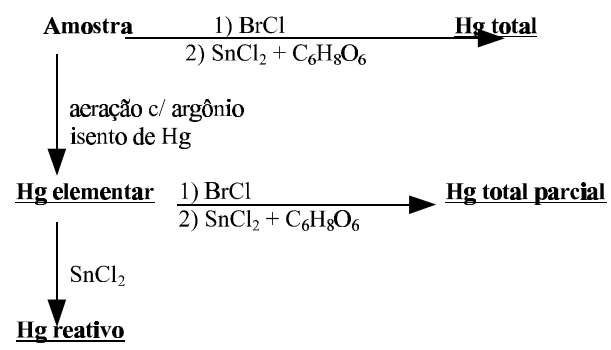

Figura 3. Fluxograma da técnica de derivatização para determinação das espécies mercúrio elementar $\left(\mathrm{Hg}^{0}\right)$, mercúrio reativo ( $\mathrm{Hg}$ react), mercúrio orgânico (Hg org) e mercúrio total (Hg tot)

Nesta técnica as amostras são inicialmente aeradas diretamente com argônio, isento de mercúrio, para a separação da fase vapor de mercúrio que é direcionada diretamente para o sistema de amalgamação em ouro do sistema de detecção (Figura 1). Essa fração representa a fase dissolvida gasosa, composta principalmente de mercúrio elementar $\left(\mathrm{Hg}^{0}\right)$ nas águas oceânicas de superfície e em estuários. Outras espécies voláteis de mercúrio (em particular dimetil mercúrio) podem estar presentes somente em águas oceânicas profundas ${ }^{13}$.

Foi realizada a otimização do volume mínimo de amostra de água do mar a ser utilizado para a determinação da espécie elementar, observando-se o limite de detecção do método utilizado.

Em seguida, uma alíquota da amostra de água desaerada é tratada com cloreto estanoso em meio ácido. Esta solução é preparada a partir da mistura de $\mathrm{SnCl}_{2}$ e ácidos fortes, na presença ou não de préredutores como ácido cítrico ou ascórbico, a diferentes concentrações ${ }^{23-25,28,29}$. Independentemente das concentrações de trabalho, a solução é sempre purificada por purga. Nessa fase do processo analítico determina-se o mercúrio reativo que representa todo o mercúrio presente na amostra na forma oxidada $\left(\mathrm{Hg}^{2+}\right.$ dissolvido e o mercúrio fracamente associado a orgânicos) ${ }^{13}$, uma vez que a fração mercúrio elementar foi previamente medida por aeração direta das amostras logo após a amostragem.

Por último, nova alíquota da amostra que já sofreu aeração para eliminação da fase gasosa dissolvida $\left(\mathrm{Hg}^{0}\right)$ é tratada para obtenção da concentração de $\mathrm{Hg}$ tot parcial que representa o mercúrio total menos a fase gasosa dissolvida. Essa fase é obtida através da oxidação de todo mercúrio restante em solução ao $\mathrm{Hg}^{2+}$, promovendo principalmente a destruição dos complexos organo-mercuriais fortes (destruição das associações fortes de $\mathrm{Hg}-\mathrm{C}$, tais como as ligações covalentes nos radicais alquila) ${ }^{30}$ ainda presentes em solução. Essa oxidação é feita através da adição de solução de cloreto de bromo, na presença de ácido ascórbico, seguida da redução à fase vapor frio, por tratamento da solução com cloreto estanoso em meio ácido, para a deteção final do mercúrio ${ }^{14}$. A oxidação prévia do mercúrio em solução pela adição de cloreto de bromo mostra melhores resultados 
do que a metodologia anteriormente utilizada, que empregava a mistura oxidante de permanganato-persulfato de potássio ${ }^{12}$.

A diferença entre o $\mathrm{Hg}$ tot parcial $-\mathrm{Hg}$ react $=\mathrm{Hg}$ org ,ou seja, a fase restante da determinação para mercúrio total é considerada, após a seqüência de determinações, como representativa da fase mercúrio orgânico fortemente associado a carbono.

Medidas em paralelo de $\mathrm{Hg}_{\text {total }}$ em subamostras foram realizadas como medida de controle analítico, para verificação do rendimento da extração das fases mercuriais. Isto é, a soma das fases $\mathrm{Hg}^{0}, \mathrm{Hg}_{\text {react }}$ e $\mathrm{Hg}$ org deve ser igual ao teor de $\mathrm{Hg}_{\text {total }}$, obtido diretamente de uma nova alíquota da amostra, utilizando-se a abertura mais oxidante. A abertura mais oxidante é aquela feita a partir da oxidação de cloreto de bromo seguida pelo tratamento da solução com cloreto estanoso em meio ácido.

\section{RESULTADOS E DISCUSSÃO}

A otimização da metodologia analítica para determinação das espécies físico-químicas mercuriais em águas costeiras tropicais demonstrou que um laboratório normal de análise de traços pode apresentar uma atmosfera inadequada ao desenvolvimento dessa metodologia. Por isso, foi necessário procedermos à preparação de um laboratório de atmosfera isenta de mercúrio, incluída a exaustão forçada da área reservada para proteção do equipamento de fluorescência, uma vez que o fabricante do equipamento menciona o fato de que a contaminação do mesmo ocorre principalmente quando o equipamento permanece em posição de stand $b y^{21}$. Foi também recomendado aos analistas do laboratório manterem cuidados especiais quanto à limpeza de uniformes adequados à sala de análise.

Todos os reagentes utilizados foram de grau analítico e a água destilada/deionizada. Entretanto, através da avaliação do branco de reagentes observou-se que vários ácidos comerciais de qualidade dita isenta de mercúrio, inclusive de classe Suprapur, não apresentam teores mínimos adequados as detecções de mercúrio em águas salinas. Assim, todo ácido clorídrico utilizado nas análises de especiação de mercúrio foi previamente destilado a baixo vácuo ou por sistema de difusão gasosa. Após a destilação, procedeu-se à titulação do ácido gerado para preparação adequada das soluções utilizadas nas análises subseqüentes.

Normalmente para preparação de soluções padrões de metais traço é feita adição de ácido inorgânico para manutenção do $\mathrm{pH} \leq 2$, para preservação das concentrações originais. Entretanto, a adição de 5,0 $\mathrm{ml}$ de $\mathrm{HNO}_{3}$ concentrado a 1,0 litro de amostra pode aumentar em $0,28 \mathrm{ng} \mathrm{L}^{-1} \mathrm{o}$ valor do branco de reagentes ${ }^{12}$. Assim, optou-se pela não adição de ácido às soluções abaixo de $1 \mathrm{mg} \mathrm{L}^{-1}$ e pela preparação diária dessas soluções. $\mathrm{O}$ consumo de padrão em pouco se altera e os resultados em termos de não contaminação dessas soluções compensam qualquer pequeno custo adicional. Dessa forma, para águas salinas as curvas de calibração foram obtidas a partir da adição de alíquotas da solução padrão de $5 \mathrm{ng} \mathrm{L}^{-1}$ ao frasco de reação (Figura 1) contendo $20 \mathrm{ml}$ de água destilada/deionizada. As curvas de calibração são construídas em unidade de massa (pg) de Hg versus absorbância.

O volume de água no frasco de reação não demonstrou ser fator relevante para o branco de reagentes da curva de calibração e tem somente função de facilitar a homogeneização e purga do vapor de mercúrio produzido nesse frasco, na fase de calibração do equipamento.

\section{Determinação das espécies $\mathrm{Hg}$}

Mercúrio elementar - $\mathrm{O}$ volume de amostra otimizado para detecção da fase mercúrio elementar em águas costeiras tropicais foi determinado em $200 \mathrm{ml}$ para esse sistema analítico (Figura 4). Entretanto, para que haja completa liberação do mercúrio elementar da amostra é necessário que a aeração, com fluxo de argônio, a $760 \mathrm{ml} / \mathrm{min}$, seja feita durante $4 \mathrm{~min}$. A partir de $4 \mathrm{~min}$ o aumento do tempo de análise não compensa a recuperação significativamente pouco maior dessa fração (Figura 5). Observou-se, também, que a divisão do tempo de aeração de 4 min em dois ciclos de 2 min, além de não alterar a programação do esquema analítico, que assim permanece o mesmo na determinação de todas as espécies-Hg, resulta num melhor rendimento (Tabela 2).

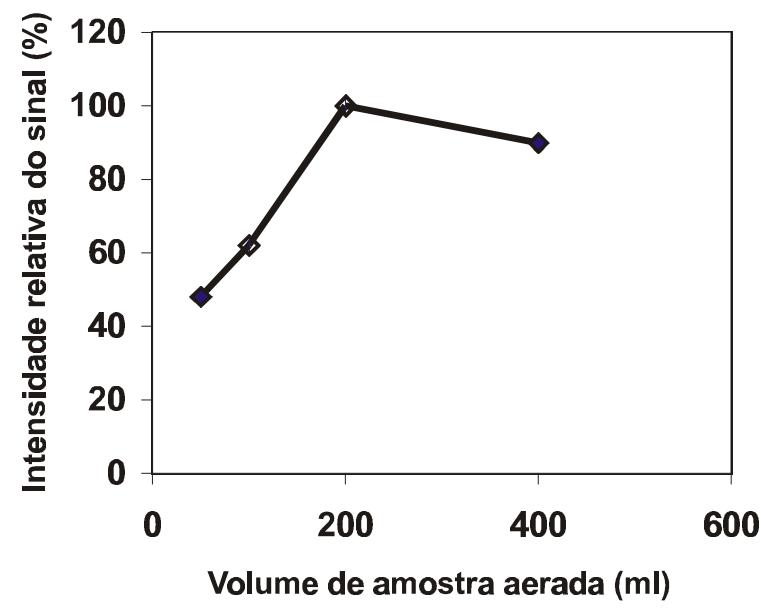

Figura 4. Resultado dos testes de determinação do volume ótimo para determinação da fase mercúrio elementar $\mathrm{Hg}^{0}$

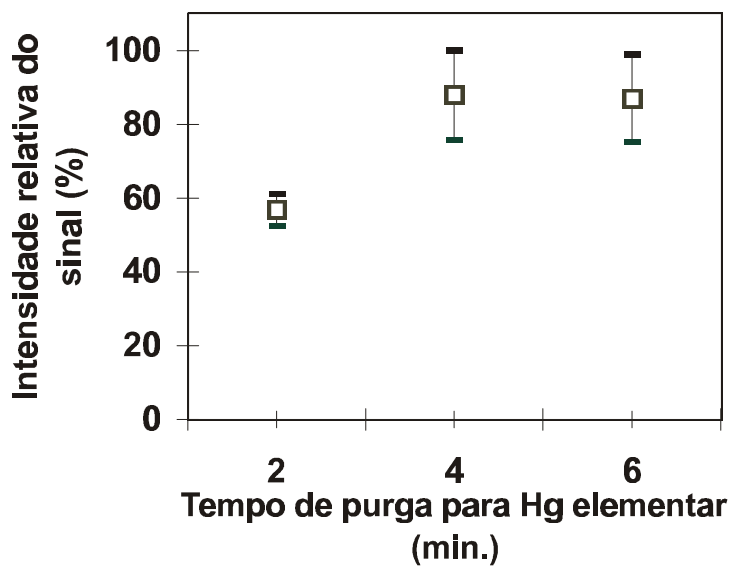

Figura 5. Avaliação do tempo de purga da amostra para determinação da fase Hg elementar

Tabela 2. Variação da intensidade de fluorescência na determinação da fase $\mathrm{Hg}^{0}$ de uma mesma amostra, variando-se o tempo de aeração com fluxo de argônio a $760 \mathrm{ml} / \mathrm{min}$ para diferentes alíquotas de 200 $\mathrm{ml}$, sendo (n) o número de replicatas testadas por amostra

\begin{tabular}{cccc}
\hline & & \multicolumn{2}{c}{$\begin{array}{c}\text { Intensidade de } \\
\text { fluorescência x }\end{array}$} \\
\cline { 3 - 4 } Amostra (n) & Tempo de aeração & Média & Desvio \\
\hline $1(7)$ & 2 min & 9,1 & 0,7 \\
$1(7)$ & 4 min & 14,1 & 1,9 \\
$1(7)$ & 6 min & 14,0 & 1,9 \\
$2(5)$ & 2 min & 17,0 & 1,7 \\
$2(5)$ & 4 min & 22,5 & 0,7 \\
$2(5)$ & $2 \times 2$ min & 30,0 & 2,0 \\
\hline
\end{tabular}


Mercúrio reativo - Dentre as misturas ácido inorgânico/cloreto estanoso apresentadas na literatura para a deteção da fase mercúrio reativo optou-se pela mistura ácido clorídrico/cloreto estanoso, devido à possibilidade de promover brancos de reagentes adequados à análise e também pela fácil obtenção do ácido clorídrico isento de mercúrio, purificado através de destilação por difusão gasosa. Essa purificação é feita a partir de ácido P.A. o que torna menor a relação custo analítico/grau de pureza do reagente adequado à metodologia em curso. Para efeito de purificação a solução redutora deve ser purgada previamente com fluxo de argônio isento de mercúrio durante $3 \mathrm{~h}$. O uso de armadilha de ouro na linha de argônio é necessário para garantir a isenção de mercúrio no fluxo gasoso.

A melhor relação encontrada entre volume de amostra e volume e composição da solução redutora foi para volumes de amostra variando de 5 a $20 \mathrm{ml}$ a adição de $1,0 \mathrm{ml}$ de cloreto estanoso a $10 \%$, contendo $1 \%$ de ácido ascórbico, em solução de ácido clorídrico 1\%. O ácido ascórbico adicionado à solução redutora atua como um pré-redutor, otimizando a pureza da solução redutora de teores de $\mathrm{Hg}$. Os melhores brancos obtidos para essa solução redutora foram os das soluções de cloreto estanoso a $1 \%$ em solução de ácido clorídrico (1\%), na presença ou não de ácido ascórbico (Figura 6). Entretanto, essas soluções demonstraram não reduzir todo $\mathrm{o} \mathrm{Hg}^{2+}$ presente em solução, em testes de rendimento de recuperação que utilizaram amostras reais de águas costeiras tropicais. Somente a solução de cloreto estanoso a $10 \%$, contendo $1 \%$ de ácido ascórbico, em solução de ácido clorídrico $1 \%$, apresentou rendimento otimizado para a redução de todo o $\mathrm{Hg}^{2+}$ presente (Figura 7). O uso de ácido ascórbico na solução redutora confere a essa maior estabilidade química, otimizando custos e tempo de análise ao torná-la útil para uma semana de uso, preservada em geladeira ao abrigo da luz (Figura 8).
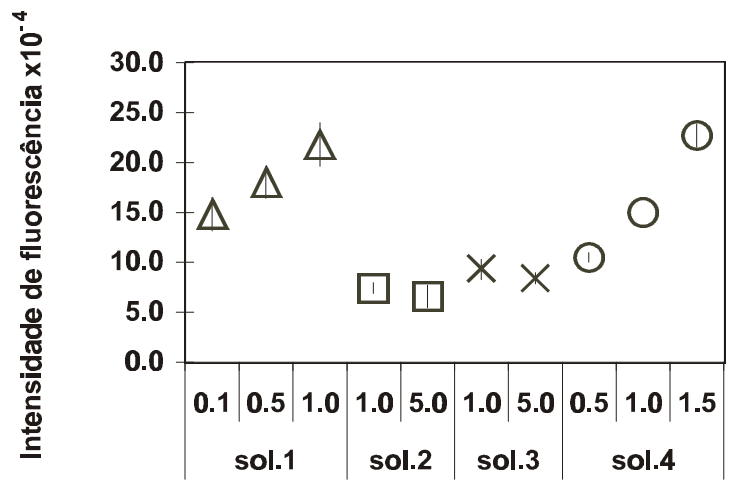

Volume de solução adicionado $(\mathrm{ml})$

Figura 6. Valores de branco de soluções redutoras dependentes da composição e dos volumes adicionados de solução. São as soluções compostas de: solução (1) - $\mathrm{SnCl}_{2} 10 \%$ em HCl $5 \mathrm{~N}$; solução (2) - $\mathrm{SnCl}_{2} 1 \%$ em $\mathrm{HCl} 1 \%$; solução (3) - $\mathrm{SnCl}_{2} 1 \%$ e ácido ascórbico $1 \%$ em $\mathrm{HCl} 1 \%$ e solução (4) de $\mathrm{SnCl}_{2} 10 \%$ e ácido ascórbico $1 \%$ em $\mathrm{HCl} 1 \%$

Mercúrio total - A oxidação de todo mercúrio restante em solução ao $\mathrm{Hg}^{2+}$, inclusive a destruição dos complexos organo-mercuriais fortes, foi realizada a partir da adição de $0,2 \mathrm{ml}$ de solução de cloreto de bromo obtida a partir da mistura (1:1) de solução de bromato de potássio $(1 \%)$ à solução de $\mathrm{HCl}(20 \%)^{11,14,28}$. Estudos realizados previamente demonstraram que a oxidação com cloreto de bromo é adequada somente para águas com baixo teor de material em suspensão ${ }^{31}$. Para águas contendo alto teor de material em suspensão, como águas fluviais, a extração ácida com água-régia $\left(3 \mathrm{H}_{2} \mathrm{O}: 2 \mathrm{HCl}: 1 \mathrm{HNO}_{3}\right)$ seguida da redução com cloreto estanoso é

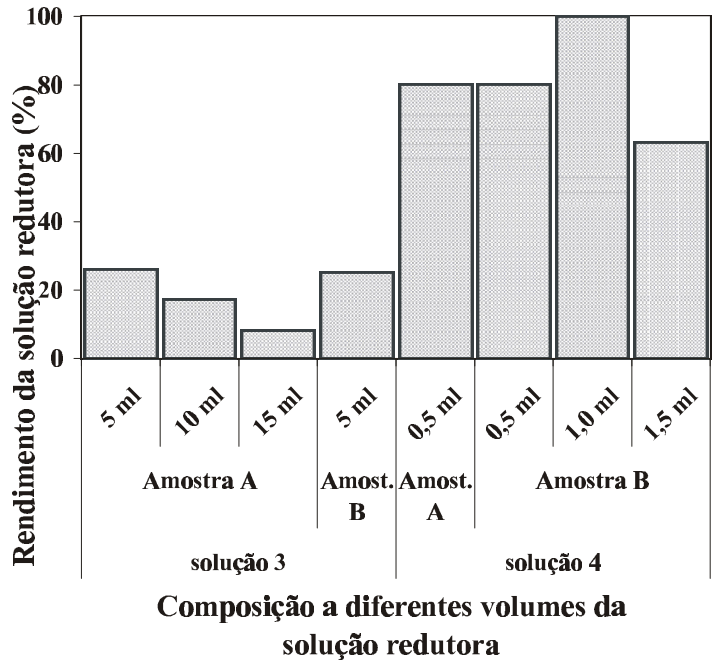

Figura 7. Rendimento das diferentes formulações de solução redutora na recuperação de todo $\mathrm{Hg}^{2+}$ presente em amostras de águas costeiras tropicais. As soluções são compostas de: Solução (3) - $\mathrm{SnCl}_{2} 1 \%$ e ácido ascórbico $1 \%$ em $\mathrm{HCl} 1 \%$; Solução (4) de $\mathrm{SnCl}_{2} 10 \%$ e ácido ascórbico $1 \%$ em $\mathrm{HCl} 1 \%$

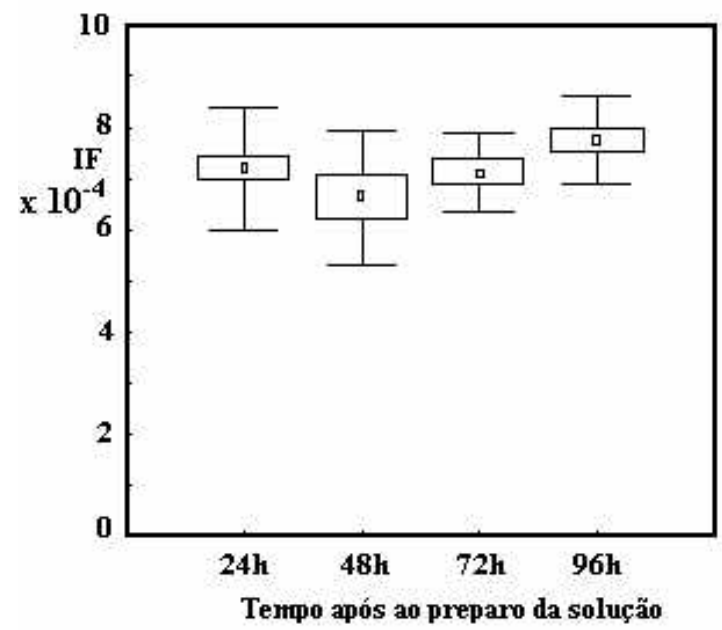

Figura 8. Estabilidade da solução de $\mathrm{SnCl}_{2} 10 \%$ em $\mathrm{HCl} 1 \%$ na presença de ácido ascórbico, sendo IF a intensidade de fluorescência

necessária para a determinação de todo mercúrio total (Tabela 3). Entretanto, o uso da solução diluída de água-régia não apresenta branco de reagente adequado para as determinações em águas costeiras tropicais ${ }^{31}$.

A adição de ácido ascórbico à solução redutora de cloreto estanoso nessa fase do processo de derivatização, além de melhorar os valores de branco de reagentes, também permite a pré-redução do excesso de cloreto de bromo adicionado à amostra. Para essa fase, a melhor relação entre volume de amostra, variando de 5 a $10 \mathrm{ml}$, e a solução redutora foi também alcançada através da adição de $1,0 \mathrm{ml}$ de cloreto estanoso a $10 \%$, contendo $1 \%$ de ácido ascórbico, em solução de ácido clorídrico 1\% (Figura 9).

Limite de deteção e rendimento do procedimento de derivatização - $\mathrm{O}$ limite de detecção (em pg) para cada uma das espécies físico-químicas foi determinado como igual a 3 vezes o desvio estimado por $\mathbf{S}_{\mathbf{y} / \mathbf{x}}$ dividido pela inclinação da reta, a partir da reta de regressão obtida da curva de calibração, assumindo-se que no método dos mínimos quadrados não ponderados, cada ponto do gráfico (incluído o ponto representativo do branco) tem uma varia- 
Tabela 3. Recuperação de $\mathrm{Hg}$ total (em nM) de amostras de águas, com teor de material em suspensão na faixa de 60 a $100 \mathrm{mg} \mathrm{L}^{-1}$, complementar a Paraquetti \& Marins ${ }^{31}$

\begin{tabular}{lcc}
\hline Águas Fluviais & $\begin{array}{c}\text { Hg total obtido por } \\
\text { oxidação com sol. } \\
\text { de cloreto de bromo }\end{array}$ & $\begin{array}{c}\text { Hg total obtido por } \\
\text { oxidação com sol. } \\
\text { de água-régia a 50\% }\end{array}$ \\
\hline Amostra 1 & 0,06 & 0,55 \\
Amostra 2 & 0,14 & 0,41 \\
Amostra 3 & $<0,06$ & 0,40 \\
\hline
\end{tabular}

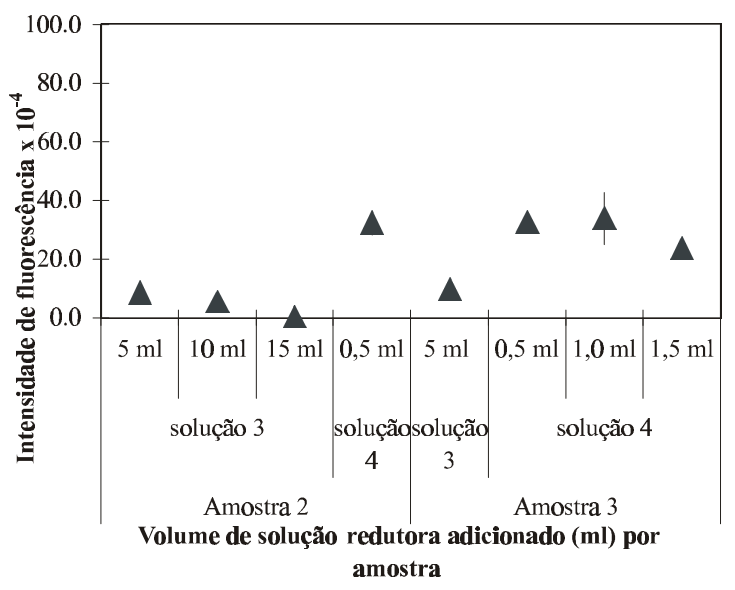

Figura 9. Recuperação do mercúrio total através de soluções redutoras diferenciadas. Solução (3) composta de $\mathrm{SnCl}_{2} 1 \%$ e ácido ascórbico $1 \%$ em $\mathrm{HCl} 1 \%$, a Solução (4) de $\mathrm{SnCl}_{2} 10 \%$ e ácido ascórbico $1 \%$ em $\mathrm{HCl} 1 \%$

ção normalmente distribuída (somente na direção de y) ${ }^{32}$, sendo Sy/ $\mathrm{x}=\left\{\sum\left(\mathrm{y}_{\mathrm{i}}-\mathrm{y}\right)^{2} .(\mathrm{n}-2)^{-1}\right\}^{1 / 2}$. Uma vez que o aparelho utilizado não dispunha de calibração por fluxo gasoso a concentração conhecida, foi necessário utilizar-se a geração de vapor de mercúrio a partir de soluções padrões de cloreto mercúrico reduzidas por solução de cloreto estanoso, nas mesmas concentrações empregadas para a obtenção das diferentes fases mercuriais. Os limites de detecção alcançados para cada espécie mercurial estão demonstrados na Tabela 4.

Tabela 4. Limites de deteção do método de derivatização para as espécies $\mathrm{Hg}$ determinadas

\begin{tabular}{lcc}
\hline Espécie química & $\begin{array}{c}\text { Limite de } \\
\text { detecção }(\mathrm{pg})\end{array}$ & $\begin{array}{c}\text { Limite de } \\
\text { detecção }(\mathrm{pM})\end{array}$ \\
\hline Hg elementar & 1,0 & 0,02 \\
Hg reativo & 1,0 & 0,25 \\
Hg total & 1,0 & 0,50 \\
\hline
\end{tabular}

Como se pode observar, os reagentes utilizados para a digestão das amostras representam importante papel na determinação dos limites de detecção das diferentes fases mercuriais, que através dos valores de branco acabam por alterar os limites de deteção de cada uma das fases.

O percentual de recuperação total das extrações das diferentes fases mercuriais comparado à concentração total apresentou resultados entre $80-94 \%$, sendo a fase mercúrio elementar provavelmente a principal responsável pelas diferenças obtidas, pois a retirada de $100 \%$ desta fração é difícil analiticamente, devido ao aumento do tempo de analise, que pode dificultar a aplicação da técnica (Tabela 5).
Tabela 5. Rendimento do procedimento analítico por derivatização para determinação de espécies $\mathrm{Hg}$ em águas estuarinas

\begin{tabular}{lccc}
\hline Frações mercuriais & \multicolumn{3}{c}{ Conc. de $\mathrm{Hg}\left(\mathrm{ng} \mathrm{L}^{-1}\right)$} \\
& Amostra 1 & Amostra 2 & Amostra 3 \\
\hline Hg elementar & 0,04 & 0,02 & 0,04 \\
Hg reativo & 0,28 & 0,42 & 0,32 \\
Hg total parcial & 0,84 & 0,83 & 0,77 \\
Hg total & 1,12 & 0,90 & 0,9 \\
Hg orgânico & 0,56 & 0,41 & 0,45 \\
Rendimento & $80 \%$ & $94 \%$ & $90 \%$ \\
\hline
\end{tabular}

\section{CONCLUSÕES}

A compreensão dos processos geoquímicos responsáveis pela ciclagem do mercúrio em águas costeiras tropicais torna-se possível a partir da otimização da metodologia apresentada para determinação de diferentes fases físico-químicas de mercúrio, utilizando-se técnica de derivatização e detecção por espectrometria de fluorescência atômica de vapor frio. Rendimentos da ordem de $80 \%$ foram obtidos nos testes iniciais. Após a otimização da composição da solução redutora, os rendimentos atingiram a faixa de 90 a $94 \%$, em relação ao teor total de mercúrio contido nas amostras.

Foi observado que os reagentes utilizados para a digestão das amostras representam importante papel na determinação dos limites de detecção das diferentes fases mercuriais que, através dos valores de branco, acabam por alterar os limites de deteção de cada uma das fases. Entretanto, com os cuidados analíticos estabelecidos foi possível detetar valores abaixo dos encontrados em amostras reais em diversos artigos apresentados na literatura internacional ${ }^{7,11,12,18}$.

Avaliações das correlações dos teores de mercúrio nas diferentes fases físico-químicas determinadas pelo método ora otimizado com carreadores geoquímicos que podem explicar o transporte, deposição e disponibilidade do mercúrio em ambiente costeiro tropical corroboram os bons resultados da metodologia de derivatização ${ }^{33,34}$.

\section{AGRADECIMENTOS}

Ao Prof. Dr. L.D. Lacerda por colocar à disposição das autoras o equipamento de fluorescência atômica. As autoras agradecem ao CNPq pelo apoio emergencial à pesquisa (Processo 420063/99-4) e bolsa RD concedidos a R.V. Marins, e pelas bolsas de mestrado de H.H.M. Paraquetti e de apoio técnico de G.A. Ayres, bem como à FAPERJ pelo auxílio à pesquisa concedido a RV Marins (Processo E-26/170.959/1999).

\section{REFERÊNCIAS}

1. Nakahara, T.; Prog. Analyt. Atom. Spectrosc. 1983, 6, 163.

2. Mota, A. M.; Gonçalves, M.L.S. Em Element Speciation in Bioinorganic Chemistry; Caroli, S., ed.; Wiley Interscience Publ.: Chichester, 1996, p. 21.

3. Kramer, K.J.M. Em Quality Assurance in Environmental Monitoring Sampling and Sample Pretreatment; Quevauviller, Ph., ed.; VCH: Weinheim, 1986, p. 179.

4. Hearn, C.J.; Lukatelich, R.J.; McComb, A.J. Em Coastal Lagoon Processes; Kjerfve, B., ed.; Elsevier: Hamburg, 1994, p. 471.

5. Marins, R.V.; Lacerda, L.D.; Villas Boas, R.C.; Em Mercury Contamination Sites: Characterization, Risk Assessment and Remediation; Ebinghaus, R.; Turner, R.R.; Lacerda, L.D.; Vasiliev, O.; Salomons, W., eds.; Springer Verlag: Berlin, 1999, p. 207.

6. Marins, R.V.; Tese de Doutorado, Universidade Federal Fluminense, Brasil, 1998.

7. Cossa, D.; Thibaud, Y.; Romeo, M.; Gnassia-Barelli, M. Em Le Mercure en Milieu Marin: Biogeochimie et Ecotoxicologie; Rapport Du IFREMER: Nantes, 1996. 
8. Clarkson, T.W. Em Mercury Pollution: Integration and Synthesis; Watras, C.J.; Huckabel, J.W., eds.; Lewis Publishers: Monterey, 1994, p. 631.

9. Mason, R.P.; O’Donnell, J.; Fitzgerald. W.F. Ref. 8, p. 83.

10. Bloom, N.S; Liang, L.; Xie, Z.Q.; Wang, S.S. Ref. 8, p. 51.

11. Mason, R.P.; Rolfhus, K.R.; Fitzgerald, W.F.; Mar. Chem. 1998, 61, 37.

12. Bloom, N.S.; Crecilius, E.A.; Mar. Chem. 1983, 14, 49.

13. Gill, G.A.; Fitzgerald, W.F.; Mar. Chem. 1987, 20, 227.

14. Gill, G.A.; Bruland, K.W.; Environ. Sci. Technol. 1990, 24, 1392.

15. Cossa, D.; Courau, P.; Appl. Organomet. Chem. 1990, 4, 49.

16. Copeland, D.D.; Facer, M.; Newton, R.; Walker, P.J.; The Analyst 1996, $121,173$.

17. Fadini, P.S.; Jardim, W.F.; The Analyst 2000, 125, 549.

18. Bloom, N.S. Ref. 8, p. 541.

19. Lakowicz, J.R.; Principles of Fluorescence Spectroscopy, Plenum Press: New York, 1983

20. Rouessac, F.; Rouessac, A.; Analyse Chimique, Masson: Paris, 1997.

21. Tekran Incorporatin; Model 2500 CVAFS Mercury Detector User Manual, Tekran Inc.: Toronto, 1996.

22. EPA. United States Environental Protection Agency; Method 1631, Revision B: Mercury in Water by Oxidation, Purge and Trap, and Cold Vapor Atomic Fluorescence Spectrometry, EPA Office of Water: Washington, 1999.
23. Pardberg, S.; Mercury Determinations in Samples from Tapajós (Itaituba). Unpubl. ms, Inst Angewandte Physikalische Chemie: Jülich, 1990.

24. Krogmann, D.; MSc. Thesis, Fachhochschule Hamburg, Alemanha, 1993.

25. Gonçalves, G.O.; Dissertação de Mestrado, Universidade Federal Fluminense, Brasil, 1999.

26. Rigin, V.I.; J. Anal. At. Spectrom. 1990, 5, 407.

27. Leermakers, M.; Meuleman, C. ; Baeyens, W.; Water, Air, Soil Pollut. 1995, 80,641 .

28. Chan, C.C.Y. ; Sadana, R.S.; Anal. Chim. Acta 1993, 282, 109.

29. Marins, R.V.; Silva Filho, E.V.; Lacerda, L.D.; J. Braz. Chem. Soc. 1996, 7, 177.

30. Nelson, L.A.; Environ. Sci. Technol. 1979, 28, 2233.

31. Paraquetti, H.H.M.; Marins, R.V.; Anais da V Jornada Interna de Iniciação Científica, CETEM/CNPq, Rio de Janeiro, Brasil, 1997.

32. Miller, L.C; Miller, J.N.; Statistics for Analytical Chemistry, Ellis Horwood and Prentice Hall: London, 1994.

33. Marins, R.V.; Lacerda, L.D.; Paraquetti, H.H.M. Proc. of Silver Anniversary Int. Conf. On Heavy Metals in the Environment, Ann Arbor, MI, 2000.

34. Marins, R.V.; Lacerda, L.D.; Mounier, S.; Ref. 33. 